\title{
Erratum to: Treadmill exercise alters ecstasy- induced long- term potentiation disruption in the hippocampus of male rats
}

\author{
Azam Sajadi $^{1}$ - Iraj Amiri ${ }^{2,3}$ - Alireza Gharebaghi ${ }^{1}$ - Alireza Komaki ${ }^{1}$. \\ Masoumeh Asadbegi ${ }^{1} \cdot$ Siamak Shahidi $^{1} \cdot$ Mehdi Mehdizadeh $^{4} \cdot$ Sara Soleimani Asl $^{1,2}$
}

Published online: 25 September 2017

(C) Springer Science+Business Media, LLC 2017

Erratum to: Metab Brain Dis (2017) 32:1603-1607

https://doi.org/10.1007/s11011-017-0046-9

In the original publication of the article, author name Masoumeh Asadbegi was incorrectly written as Masoumeh Asadbeigi.

The authors regret the oversight.

The online version of the original article can be found at https://doi.org/ 10.1007/s11011-017-0046-9

Sara Soleimani Asl

s.soleimaniasl@umsha.ac.ir

1 Neurophysiology Research Center, Hamadan University of Medical Sciences, Hamadan, Iran

2 Anatomy Department, School of Medicine, Hamadan University of Medical Sciences, Hamadan, Iran

3 Endometrium and Endometriosis Research Center, Hamadan University of Medical Sciences, Hamadan, Iran

4 Cellular and Molecular Research Center, Faculty of Advanced Technologies in Medicine, Department of Anatomy, Iran University of Medical sciences, Tehran, Iran 